\title{
Mindful Sustainable Consumption and Sustainability Chatbots in Fast Fashion Retailing During and After the COVID-19 Pandemic
}

\author{
Marzia Del Prete ${ }^{1}$ \\ ${ }^{1}$ DISES Department, University of Salerno, Salerno, Italy \\ Correspondence: Marzia Del Prete, DISES Deparment, Univerisity of Salerno, via Giovanni Paolo II, 132 - \\ 84084 Fisciano (SA), Italy.
}

Received: October 30, 2021

Accepted: December 13, $2021 \quad$ Online Published: January 8, 2022

doi:10.5539/jms.v12n1p19

URL: https://doi.org/10.5539/jms.v12n1p19

\begin{abstract}
The COVID-19 pandemic and ecological crisis are paving the way for new consumption models based on customers' conscious choices and the subsequent integration of sustainable policies into retailers' business strategies. As a consequence, the current consumer trends suggest that more people are becoming aware of their consumption standards and their repercussion on the environment and society. Statistics demonstrate that, in their purchasing processes, these "mindful customers" now search for a sustainable, self-sufficient way of living in harmony with nature. This paper argues that artificial intelligence (AI) is able to facilitate this process in the marketplace. More specifically, mindfulness with the support of AI technologies could be a plausible way to activate sustainable consumption patterns for avoiding overconsumption. The life-changing ability of mindful consumption is reviewed in this paper across domains of sustainability. Using a comprehensive literature review, the paper first outlines the theoretical and conceptual foundations of the mindful sustainable consumption (MSC) approach that fills the literature gap that almost always separates mindful consumption from sustainability. Second, the new conceptual approach is applied through a strategic framework in the field of fast fashion retailing through the use of AI-powered chatbots. In particular, the study defines a new category of chatbots, named sustainability chatbots (SC), which could convey mindful and sustainable consumption choices. The paper highlights that the MSC approach combined with the support of SC could enable marketing managers to create the appropriate context for embedding sustainability into consumer behaviour and fast fashion retailers' strategies from a value co-creation perspective.
\end{abstract}

Keywords: mindful consumption, sustainability, chatbot, fast fashion retailing, Covid-19 pandemic

\section{Introduction}

Mindless consumption is a crucial issue to environmental, social, and individual well-being (Bahl et al., 2016). Customer's consumption choices are determined by a plethora of uncontrolled emotions, impulses, habits, compulsions, and decision biases that manage the customer journey every day (Schulte, 2014). An uncontrolled bombardment of information from different channels, without a true awareness of customer's emotions, induces customers to make irrational consumption choices. The COVID-19 pandemic and the ecological crisis have accelerated the need to implement changes in the lives of the worldwide population by clearly changing habits, routines, and decisions (O’Brien, 2018; Ives et al., 2019).

According to a BCG survey (Covid-19 and Environment, 2020) with over 3,000 respondents from eight countries, about $70 \%$ of participants affirm that the COVID-19 pandemic has increase their awareness that humans are responsible of climate and environmental changes. Over $60 \%$ of respondents said that the environment must become an economic priority. From a personal level, $40 \%$ of the sample would adopt more sustainable behaviours in the future. Additionally, $87 \%$ of them said companies should integrate sustainability in their business strategies. Younger people are more committed to sustainability, as they believe personal behaviour can make a difference in addressing environmental issues and expect environmental issues to be at the centre of recovery plans. The crisis has also accelerated the use of digital and artificial intelligence (AI) systems and this paradigm may persevere post-crisis. Companies have begun to communicate, engage, and interact with customers fully utilising the potential of the existing technology-mediated channels. In the consumer surveys conducted by McKinsey (started in March, 2020) to understand the impact of COVID-19 on consumer sentiment and behaviour, it was noted that the customers would buy more online, but in ways that were less irrational and 
compulsive. For this reason, the COVID-19 pandemic rekindled the debate within research on mindful consumption and sustainability, which are becoming part of corporate strategy as a consequence of the changing consumer trends. One primary goal of transformative consumer research is to empower customers to make conscious consumption decisions for promoting individual, social, and environmental well-being (Bahl et al., 2016; Mick et al., 2012). One possible way is to develop "mindfulness", which is the ability to pay attention to the present moment without judgment (Kabat-Zinn, 1994). Researchers such as Thierman and Sheate (2020), Siqueira and Pitassi (2016) and Wamsler et al. (2017) have studied how mindfulness impacts sustainability and pro-environmental behaviour (PEB).

They have paid significant attention to mindfulness as a means of disrupting automatic routines, enhancing awareness and fostering prosocial values and behaviours as part of the research on sustainable consumption (Stanszus et al., 2017). Although authors such as Amel et al. (2009) suggesting a positive interrelation between mindfulness and sustainable consumption exists, mindful consumption and sustainability are often treated as separate topics in literature. In fact, some researchers warn that mindfulness cannot be the medicine that treats environmental and social disasters (Thierman \& Sheate, 2020; Kabat-Zinn, 2017; Van Dam et al., 2018; Singer \& Engert, 2019).

The purpose of this paper is to fill the gap in the literature by combining the two topics in a unique conceptual approach defined as mindful sustainable consumption (MSC). A key assumption in the study is that MSC has the ability to direct the customer's consumption choices towards sustainability - understood as the individual/social, environmental, and economic well-being - due to the support of new emerging technologies, such as artificial intelligence (AI).

Surely, AI-powered chatbots (or conversational agents) and digitalisation may offer customers new ways for interacting with firms and receiving environmental and ethical information (Fuentes \& Sörum, 2019). A chatbot can provide customer information or technical assistance and is increasingly being used as the customer's first point of contact with the firm (Brady, 2018).

In this paper, it is argued that next to customer care chatbots, every firm should equip itself with sustainability chatbots (SC) capable of leading customers to a paradigm shift towards MSC. From the point of view of retailers, MSC could be the conceptual tool needed for integrating sustainability into business strategy. MSC enables retailers to offer new consumption possibilities focused on recycling and rental, involving customers directly in value co-creation (Vargo et al., 2008).

Accordingly, the study is guided by three main research questions:

RQ1: How to combine mindful consumption with sustainability in a unique conceptual approach?

RQ2: How and why to implement MSC in fast fashion retailing?

RQ3: How could artificial intelligence accelerate the application of the proposed approach in fast fashion retailing?

By integrating key concepts, the proposed MSC approach highlights relevant aspects to consider in the fast fashion retailing sector, particularly during and after the COVID-19 pandemic. The paper is organised into three sections. First section includes the introduction of the theoretical path of mindfulness and sustainability for the new MSC approach and the limitations of the application of this model in fast fashion retailing. Second section highlights a focus on how the MSC approach has the potential to be implemented in fast fashion retailing through SC for engaging the "new mindful customer". Finally, the paper discusses the implications of the MSC approach and SC for customers, fast-fashion retailers, and marketing managers, as well as the limitations and potential future research areas.

\section{Theoretical Foundations}

Guided by RQ1, RQ2 and RQ3, this study highlights the theoretical aspects of mindfulness in consumer behaviour related to sustainability research (Milne et al., 2020; Amhel et al., 2009; Armstrong, 2012; Brown \& Kasser, 2005; Fischer et al., 2017; Jacob et al., 2009) despite treated as two separate topics in the literature. Subsequently, the fast fashion sector is analysed because it is regarded as one of the most polluting industry for the environment and extremely far from the logic of mindfulness and sustainability. For this reason, with the support of SC, the MSC approach could find an ideal application within the fast fashion sector.

\subsection{Mindfulness}

For a sustainable planet, it is optimal to engage people in sustainability by changing their inner dimensions and strengthening systems thinking (Saviano et al., 2017; O’Brien, 2018; Wamsler, 2018, 2019; Ives et al., 2019). 
The human nature and the natural environment are closely related (Thierman \& Sheate, 2020). In order to enable customers to be truly sustainable, a new paradigm of mind over body, head over heart, and people over nature is needed (Livingstone, 2019).

Mindfulness is a condition of human consciousness; the capacity to pay attention to the present moment without judgement (Kabat-Zinn, 1994, 2003) and independently from religious, spiritual, or cultural beliefs (Black, 2011) This definition is in accordance with that of many other authors. For example, Hanh (1976) defined mindfulness as the ability to keep one's consciousness alive to the present reality. Marlatt and Kristeller (1999) defined mindfulness as bringing one's full attention to the present moment. The concept of mindfulness converges with a non-judgmental observation of internal and external stimuli as they arise (Baer, 2003) and consists of two essential elements (Bishop et al., 2004). The first element involves self-regulation to resolve the problems and the second involves approaching one's experience with curiosity, acceptance and without judgment. Mindfulness, therefore, is a type "of non-elaborative, non-judgmental, present-centred awareness in which each thought, feeling or sensation is acknowledged and accepted as it is" (Bishop et al., 2004, p. 232) in the present moment (Gilpin, 2008).

MBSR programs contribute not only to stress reduction through mindfulness practices but also to the improvement of individual well-being and health-related patterns (e.g., panic reduction, enhancing the immune system or the meaning of life) (Kabat-Zinn, 2003; Chambers et al., 2009). In consumer research, unmanaged stress and anxiety activate mindless consumption. Mindfulness works by "disengaging individuals from automatic thoughts, habits, and unhealthy behavior patterns" (Brown \& Ryan, 2003, p. 823) and increases self-awareness, motivation, self-acceptance, self-compassion and empathy (Fischer et al., 2017; Bolz \& Singer, 2013; Shapiro et al., 1998). Although MBSR initially gave important empirical results in the field of medicine, psychology, and neuroscience (Kabat-Zinn et al., 1985; Kabat-Zinn et al., 1987; Siegel, 2001), in recent years it has become a practical tool for making mindfulness an interdisciplinary research subject. In transformative consumer research, the applications on mindfulness demonstrate that it enables customers to make better choices in the marketplace for their personal and social well-being through an open awareness during consumption. The practice of mindfulness meditation, through an MBSR program, results in both focused attention and open awareness in the mind (Badham \& King, 2021; Lutz et al., 2008). Focused attention creates nonjudgment, compassion and flexibility (Kabat-Zinn, 2013). In particular, nonjudgement does not mean being unable to distinguish stimuli as positive or negative; in fact, such behaviour would undoubtedly affect consumption decisions. Rather, non-judgmental consideration of stimuli ensures a better evaluation because it discourages automatic mechanisms (Brown et al., 2009). Self-compassion within the consumption context connects customers with society and environment (Rosemberg, 2004). Cognitive flexibility (Moore \& Malinowsky, 2009) is necessary to consider various perspectives in the consumption process.

In terms of open awareness, mindfulness increases access to information (Bishop et al., 2004) and customer's choices are not determined by pleasure or avoidance of pain (Bahl et al., 2016). Once these mindful competences are learned, mindfulness becomes a soft skill of the mind outside of the meditation practice to manage stressful or emotionally negative experiences (Bishop et al., 2004), which are often the cause of overconsumption.

\subsection{Mindful Consumption and Sustainability}

Mindful consumption is defined by Sheth et al. (2011) as a customer-centric approach to sustainability. In Figure 1 , the customer-centric sustainability (CCS) concept assesses the impacts of marketing actions and related customers choices on the three dimensions of sustainability (environmental, social, and economic) (Sheth et al., 2011). 


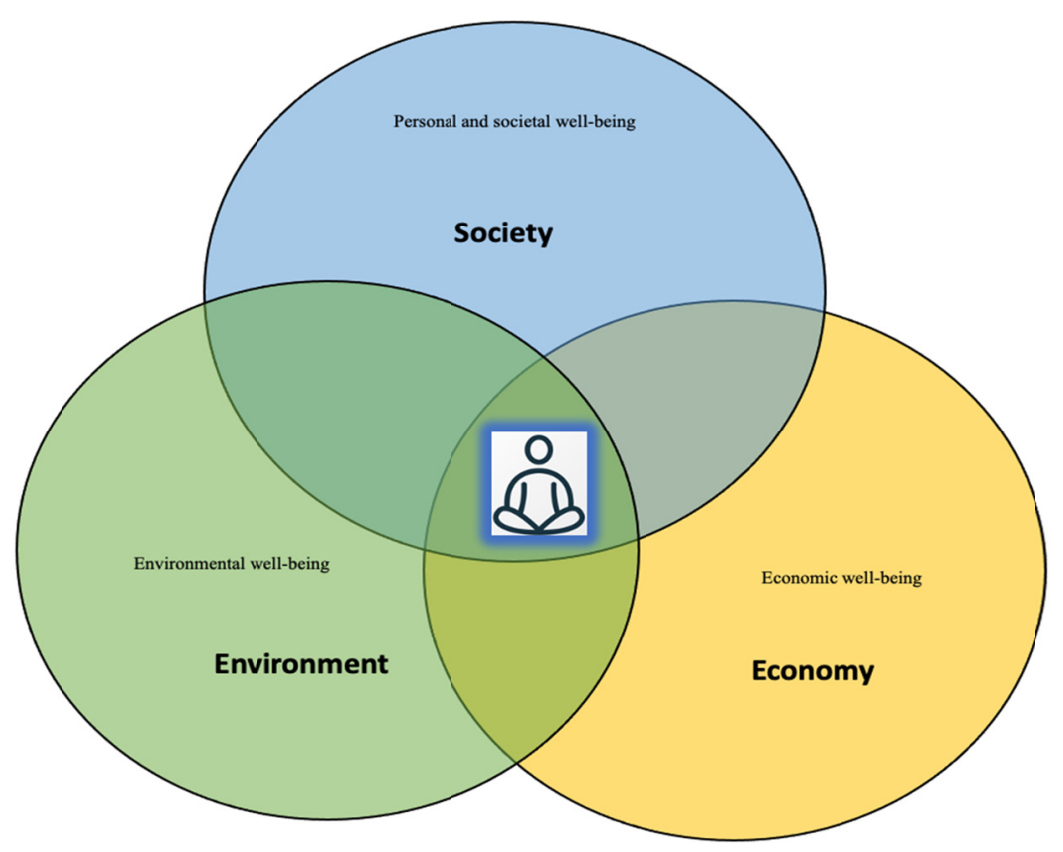

Figure 1. Mindful consumption as a CCS concept

The environmental dimension is influenced by consumption in terms of environmental well-being, which in turn has an impact on the well-being and health of individuals who are affected by climate and environmental changes triggered by unaware consumption choices. The social dimension is related to consumption through personal and family well-being, often reflecting the prosperity of the community; and, the economic dimension is related to economic well-being often associated with debts, earnings and work-life balance (Sheth et al., 2011).

The confluence of a mindful mindset and mindful behaviour in customer choices are required for environmental, social, and economic well-being (Bahl et al., 2016).

A mindful mindset is represented by a deeper care for oneself, for the society, and for the environment. Excessive behaviours associated with acquisitive, repetitive, and aspirational consumption can be moderated by mindful behaviour (Table 1).

Table 1. Mindful mindset and mindful behaviour and their core attributes

\begin{tabular}{|c|c|}
\hline Mindful Mindset & Mindful Behaviour \\
\hline Caring for self means paying attention to personal well-being. & $\begin{array}{l}\text { Acquisitive consumption means buying goods beyond the consumption } \\
\text { capacity (for example a buffet). }\end{array}$ \\
\hline $\begin{array}{l}\text { Caring for the community is about both societal and } \\
\text { individual well-being (Chan \& Li, 2010; Dennis et al., 2016). }\end{array}$ & $\begin{array}{l}\text { Repetitive consumption is the cycle of constant buying of products such } \\
\text { as technological and/or fashion products. }\end{array}$ \\
\hline $\begin{array}{l}\text { Caring for nature is to pay attention to intrinsic and auxiliary } \\
\text { values (Kilbourne, 2006; Winter, 2007). }\end{array}$ & $\begin{array}{l}\text { Aspirational consumption is acquisitive consumption (Lertwannawit \& } \\
\text { Mandhachitara, 2012; Veblen, 1899; Zhan \& He, 2012) not only for } \\
\text { consumers with a large spending capacity but increasingly to the } \\
\text { prerogative of the average consumer as well (Kastanakis \& Balabanis, } \\
2012,2014 \text { ). }\end{array}$ \\
\hline \multicolumn{2}{|l|}{ Core attributes } \\
\hline Care & Temperance \\
\hline
\end{tabular}

Source: Sheth et al., 2011.

The core value of the Mindful Mindset is caring, while the core of Mindful Behaviour is tempering consumption for enhanced personal well-being in relation to personal values (Figure 2). 


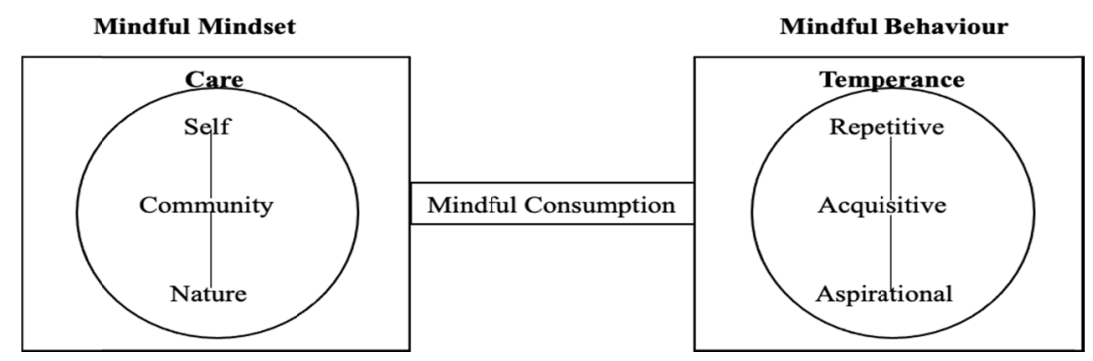

Figure 2. Mindful consumption

Source: Sheth et al., 2011.

The mindset developed through mindfulness demonstrates a better engagement in relation to oneself, community, and nature by reinforcing temperance in consumption practices. In terms of sustainability, this means a greater attention on personal and environmental values that may function to moderate the effects of mindless practices (Ericson, 2014).

Mindfulness is not only as a practice to feel better (Thierman \& Sheate, 2020; Garland et al., 2015; Kasser, 2017; Hunecke \& Richter, 2019). Fischer et al. (2017) argued that mindfulness also encourages sustainable consumption, through 1) the disruption of routines, 2) a more congruence of one's attitudes and behaviours, 3) non-materialistic wellbeing, and 4) pro-social behaviour (Milne et al., 2020).

\subsection{Fast Fashion Retailing: A Great Challenge for Mindful Consumption and Sustainability}

Customer's unpleasant habits is a significant limit to PEB when unattended emotions and impulses control the customer (Thierman \& Sheate, 2020; Klöckner \& Verplanken, 2019). Mindfulness acts in the reduction of automatic and impulsive behaviour due to an increased awareness that supports better regulation of emotions (Chambers et al., 2009; Hölzel et al., 2011). Extensive research shows the link between the benefits of mindfulness and PEB (Whitburn et al., 2019; Schutte \& Malouf, 2018; Aspy \& Proeve, 2017; Hamann \& Ivtzan, 2016; Unsworth et al., 2016; Djernis et al., 2019; Howel et al., 2011; Barbaro \& Picket, 2016; Hanley et al., 2017; Werner et al., 2020). It is more prevalent in some industries, such as fast fashion, that customers practice unhealthy habits. Thus, these industries are highly polluting for the environment as well as not very pro-social. Sustainability challenges also imply questions of social justice (Costello et al., 2009), social welfare and nature (Thierman \& Sheate, 2020). Fast fashion companies often exploit child labour and use highly polluting plastic fibres.

The attitude to feel empathy and to connect with others, is assumed to be a crucial element for ecological and environmentalist behaviours (Tam, 2013; Pfattheicher et al., 2016). Empathy, compassion, and altruism (pro-social tendencies), which mindfulness strengthens (Kreplin et al., 2018; Donald et al., 2018; Singer \& Engert, 2019; Panno et al., 2018; Loy \& Reese, 2019), have an impact on PEB (Thiermann \& Sheate, 2020).

Fast fashion retailing is characterised by cheap fashionable clothes, designed by fashion designers or celebrities, and sold in offline and online stores for a mass market (Rauturier, 2018). As a result of their short lifespan, the garments are designed to be quickly replaced (Stottlemire, 2017). Cobbing and Vicaire (2016) identified profound changes in the mechanisms of consumption for fast fashion apparel; customers no longer bought out of necessity and according to the changing seasons but by impulse. For these "unaware" customers shopping became a form of entertainment; they are able to buy beyond all logic for pure fun and without often wearing the garments more than once. Fast fashion has become a means of overconsumption and materialism (Cobbing \& Vicaire, 2016). Overconsuming may be caused by negative emotions and moods (Sohn \& Choi, 2014). Shopping, in fact, increases positive emotions such as joy and happiness, especially in the short term due to the "retail therapy" (Benson, 2008; Sohn \& Choi, 2014). In contrast, mindful customers are not governed by stress and tend to buy durable and eco-friendly garments. From a retailer's perspective, the compulsive consumption has led to fast fashion becoming a business strategy (Fernie \& Sparks, 2004). Fast fashion clothing stores have a short lifecycle and can only be in stores for a few weeks or months at most (Christopher et al., 2004). Contrary to the luxury fashion brands, fast fashion businesses have to offer their customers more fashion collections with lower prices (Barnes \& Lea-Greenwood, 2006; Bruce \& Daly, 2006; Sheridan et al., 2006; Sull \& Turconi, 2008).

A crucial aspect is the burden on suppliers to respond promptly to changing fashion trends (Barnes \& Lea-Greenwood, 2010). The fast fashion retail system is characterized by flexible design processes and quickly responses in the supply chain (Cachon \& Swinney, 2011). 
Fast fashion retailing is a great challenge for sustainability with important environmental, social and economic results. Production reduces the planet's resources by increasing the demand for natural and synthetic fibers that depend on agriculture and petroleum (Muller et al., 2017). Creating more apparels increases energy consumption and $\mathrm{CO}_{2}$ pollution as new clothes are shipped every two weeks to stores around the world (Anguelov, 2015). Additionally, fast fashion manufacturing raises humanitarian concerns as the business model depends on low-cost products and child labor, which often conflict with acceptable working conditions, a fair wage, and common ethics.

\subsubsection{Fast Fashion Retailing and Artificial Intelligence}

The useful application of artificial intelligence (AI) has been recognised in fast fashion retailing (Guo et al., 2011; Nayak \& Padhye, 2018). With the emergence of COVID-19, AI has gained attention for its ability to stem the volatility of the fast fashion sector and continuously evolving customer's demands. In the past, the fast fashion sector utilised AI for improving supply chain processes like apparel production (Lee et al., 2012), fabric inspection (Nasira \& Banumathy, 2014) and distribution (Chen et al., 2014).

Recently, the creation of digital platforms in fast fashion retailing can be attained by utilising artificial intelligence (AI), big data analytical tools and other current technologies such as the internet of things (IoT) (Acharya et al., 2018).

Fashion brands are using AI-powered chatbots to help customers create personalised experiences. A chatbot is an AI-powered program that simulates a real human conversation through a text-based input and an output mask. These conversational agents allow customers to communicate with machines as if they were in the presence of a real frontline employee (Wang \& Petrina, 2013). Chatbots, regardless of their functions, are mostly associated with messenger apps rather than software programs (Panesar, 2020) and use machine-learning processes to analyse the customers' requests and to answer them as accurately as possible. In addition, some chatbots use the deep learning technique that can process a large amount of unstructured data (Dempt, 2016).

The aim of this paper is to bring different theoretical aspects in the mindful sustainable consumption approach (MSC), linking it to the new artificial intelligence technologies to offer several implications, in particular, for polluting and environmentally harmful sectors such as fast fashion retailing. The MCS approach using sustainability chatbots is able to help marketers co-create the value of sustainability for customers and retailers.

\section{From Mindful Consumption to the Mindful Sustainable Consumption (MSC) Approach}

This conceptual study highlights how mindfulness could promote changes in customer behaviours through four main facets referring to both mindful mindset and mindful behaviour (Figure 3).

Mindfulness practices, in particular, can enhance 1) non-material values increasing the importance of non-material behaviours in customer decisions (Ericson et al., 2014). Mindfulness is one approach to prevent unsustainable practices by cultivating awareness, empathy, compassion and mental openness. The investigation of oneself is essential for maintaining an open attitude to any human experience, positive or negative.

As a consequence, mindfulness can trigger healthy mental habits in the individual that can turn into pro-social and environmental behaviours (Burroughs \& Rindfleisch, 2002; Kasser et al., 2014; Richins \& Dawson, 1992).

The essential ethical functions of mindfulness needed to create a mindful mindset are 2) pro-social behaviours (the outcomes of meditation practices) (Lim et al., 2015). Loving-kindness meditation or metta meditation, for example, increases compassion (Condon et al., 2013) and pro-social values (Leiberg et al., 2011). In particular, pro-social or altruistic behaviours have a regularly positive impact on different environmental values (de Groot \& Steg, 2008; Steg et al., 2014; Ericson et al., 2014; Fischer et al., 2017; Thiermann \& Sheate, 2020) and are identified as a crucial aspect for people's motivation to reduce waste and polluting behaviours (Howell, 2013).

For generating mindful behaviour, mindfulness may entail 3) disrupting routines by enhancing individuals' ability to observe and change unconscious habits (Grossman et al., 2004). For sustainable consumption, this means to minimize non-sustainable consumption choices (Rosenberg, 2005; Bahl et al., 2016) in relation to repetitive, acquisitive, and aspirational behaviours.

The perception of self-inattention to everyday experiences is often related to the attitude-behaviour gap (Chatzisarantis \& Hagger, 2007). Mindfulness implies 4) congruence by enhancing awareness of daily life experiences; therefore, this practice may contribute to the closing of the attitude-behavior gap, which in turn supports more sustainable consumption attitudes (Ericson et al., 2014; Rosenberg, 2005). Environmental psychologists agree that customers with strong altruistic and biospheric values are more likely to get committed in PEB than those guided by materialistic values (Thiermann \& Sheate, 2020; Hedlund-de Witt et al., 2014; Steg, 
2016; de Groot \& Thøgersen, 2018; Gatersleben, 2018).

This paper argues that a customer's open awareness of non-material values and pro-social behaviours is linked to a sustainable mindset, while the disruption of routines and a congruent focused daily customer experience create a sustainable behaviour. In this model, mindfulness becomes the element that allows customers to implement a sustainable mindset and sustainable behaviour (Figure 3).

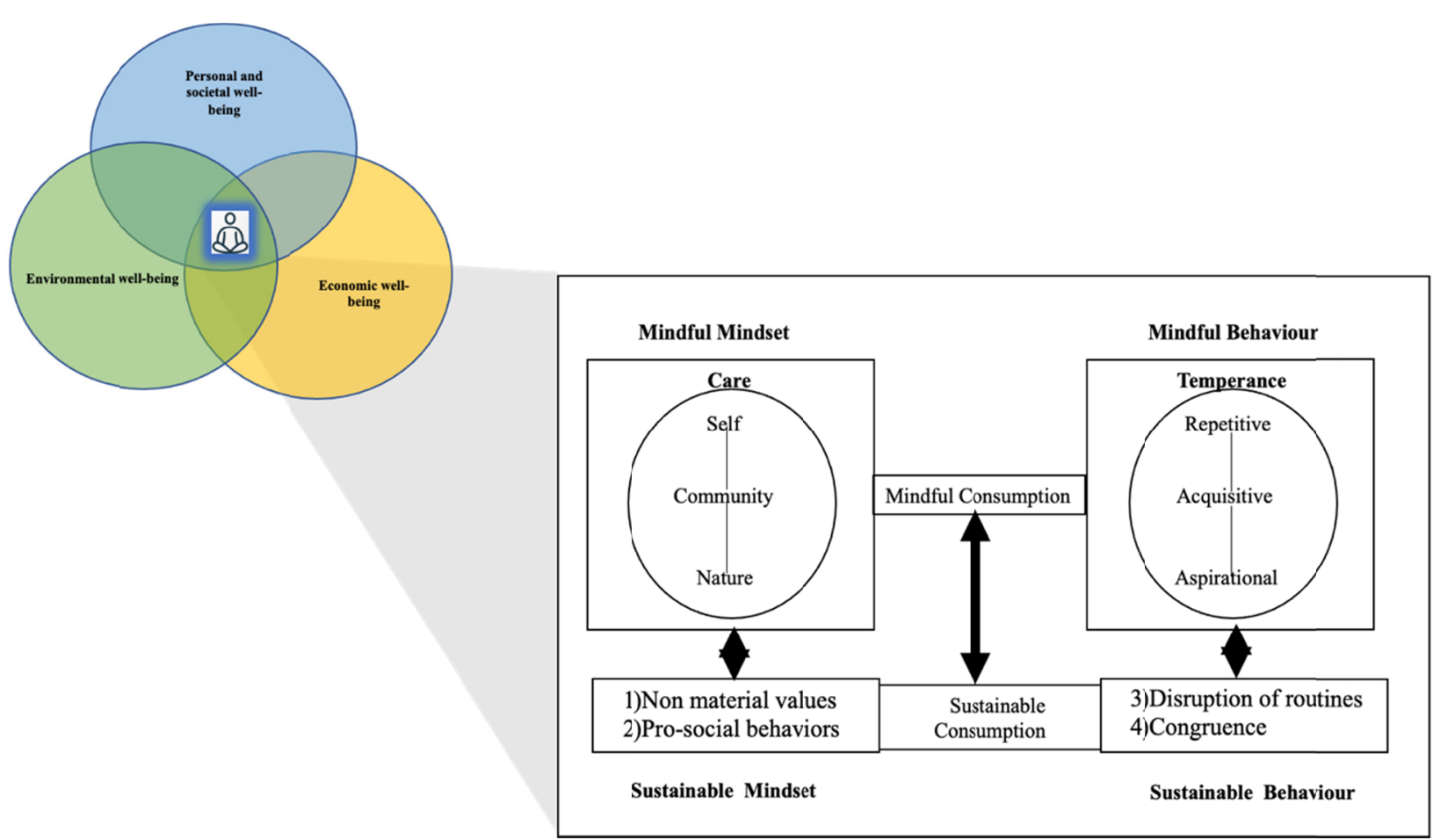

Figure 3. Mindful sustainable consumption approach

The mindful sustainable consumption approach (MSC) highlights the connection, hitherto unexplored in research, between mindful consumption and sustainability. A mindful customer is an individual who cares and respects himself, others, and the world in which he lives. He can manage his impulses by breaking the automatisms and forming healthy mental habits devoted to sustainable consumption by focusing on internal stimuli and being open to external stimuli. Retailers need to prepare for this paradigm shift by integrating sustainability into their business models. As a result of mindful consumption on the demand side, retailers must align their business strategies with sustainability on the supply side, as mindful consumption is able to activate sustainable consumption. Through the MSC approach, the first assumption is that customers and retailers collaborate by co-creating the value of sustainability. This implies that driven by mindful consumption, retailers have the possibility to think of new business models dedicated to recycling, renting, or exchanging and thereby directly involving customers in the supply chain. To support the MSC conceptual model, the goal of this paper is to make a practical application in a specific sector, such as that of fast fashion retailing, which was hit hard by the COVID-19 pandemic.

\subsection{Implementing the MSC Approach in Fast Fashion Retailing}

Recently, customers of the fast fashion industry have become progressively receptive of the environmental and societal damage of the current retailing strategies (Bick et al., 2018). Brands and retailers have started to implement specific environmental and social initiatives, both individually and through non-profit organisations. However, these actions are conducted for reducing the impact of materials, rather than co-creating the value of sustainability by increasing the use of fast fashion products through the rent, exchange or recycling as proposed in this paper.

The MCS approach in fast fashion retailing may activate a series of these mindful choices and sustainable practices aimed at safeguarding of the environment and society (Figure 4). 


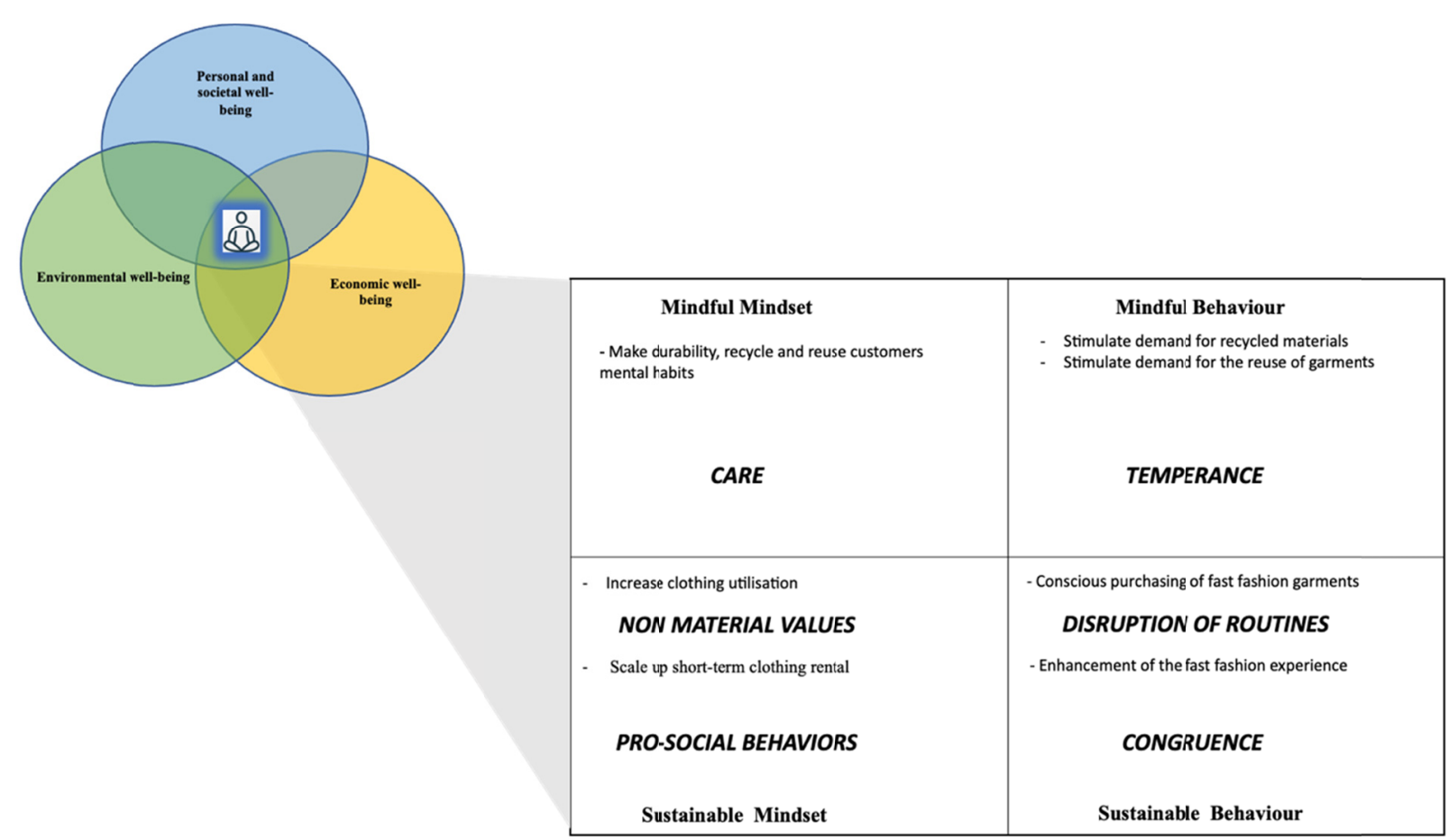

Figure 4. The MSC approach in fast fashion retailing

In particular, the MSC approach for fast fashion identifies customer's mindful and sustainable behaviours and/or practices in four quadrants: 1) Mindful Mindset, 2) Mindful Behaviour, 3) Sustainable Mindset, 4) Sustainable Behaviour.

1) Mindful Mindset. Make durability, recycling, and reuse part of customers' mental habits

The MSC approach aims to incentivise information on the durability, recycling, and reuse of products to convey awareness in the customer's choices to create a mindful mindset devoted to personal, social, and environmental well-being. Rather than stimulating the demand with the production of continuous new collections (that involve the excessive exploitation of environmental resources and low-cost labour in the least developed countries), the MSC approach, through the use of AI technologies, has the potential to convey correct information on the benefits of recycling and reuse by triggering virtuous mechanisms throughout the supply chain.

2) Mindful Behaviour

\section{- $\quad$ Stimulate demand for recycled materials}

The MSC approach aims to engage customers in clear commitment to clothing recycling. According to this approach, a better encounter between customers and firms supported by an increased transparency due to the use of AI technologies would further help stimulate mindful behaviours for recycled materials, triggering a virtuous circle within the supply chain.

\section{- Stimulate demand for the reuse of garments}

To alleviate the compulsive and anxiety-provoking choices triggered by the overproduction of fast fashion collections, the MSC approach aims to make the customer aware of choosing apparels that last: a sector transition that could be supported through sustainability standards, cooperative rather than competitive efforts and greater transparency. This awareness could be activated through educational and training moments using artificial intelligence tools such as chatbots. Mindful behaviours regarding the reuse of fast fashion products can be represented by exchange, rent and loan by other users and/or retailers, in a fair and inclusive logic.

\section{3) Sustainable Mindset}

\section{- Increase clothing utilisation (non-material values)}

The MSC approach aims to stimulate non-material values. In addition to short-term clothing rental, enhanced resale models offer an attractive option for "vintage" clothes that can be used again. New technologies such as AI-powered chatbots are able to offer a better fit and customisation for the unused garment for maximum 
customer satisfaction.

- $\quad$ Scale-up short-term clothing rental (Pro-social behaviours)

According to the MSC approach, the short-term clothing rental has the potential to activate pro-social behaviours. For compulsive clothing shoppers, subscription-based models offer the convenience to receive always new clothes. These new business models based on refocusing retailers' marketing strategies using the brand's image and improving logistics can promote new service offerings. AI-powered chatbots are able to propose and support these new paradigms.

4) Sustainable Behaviour

- $\quad$ Conscious purchasing of fast fashion garments (Disruption of routines)

The MSC approach aims to disrupt routines in relation to the compulsive and meaningless purchasing of fast fashion products by creating awareness of environmentally damaging products and making consumers aware of what they are buying. Conscious consumption could allow the whole sector to innovate by using raw materials created by recycling fashion products or waste from other sectors. For example, creating running shoes from plastics recovered from the oceans. AI-powered chatbots are able to inform customers about the composition and materials of the products.

\section{- Enhancement of the fast fashion experience (Congruence)}

The MSC approach aims to enhance customers' daily experience of fast fashion products, making purchases congruent with the product's frequency of use and with the real needs of the customer. This means not buying more products to use them only once or only because stimulated by the new collections. Enhancing the shopping experience means being able to go beyond the product itself to emotionally connect with brands and other users in a logic of comparison, exchange, sharing of choices but also of emotions, memories and situations experienced wearing those garments. The chatbot becomes a tool that facilitates the storytelling of the product, making it unique for the customer and therefore not replaceable.

\subsection{Sustainability Chatbots (SC) in Fast Fashion Retailing}

Chatbots use text, web views, graphic images, and product photos to create intuitive experiences. They are a useful tool for conveying the MSC approach in fast fashion for the reasons discussed above. When properly configured for sustainability, chatbots can raise awareness about the composition, use, and durability of garments by recommending the most appropriate solutions to the customer in an informal way, incorporating multimedia elements that provide even more value and allow personalization of the experience. This paper introduces the concept of sustainability chatbots (SC) to inform and engage customers in mindful and sustainable choices. SC could also offer educational modules on mindful and sustainable consumption to enhance the awareness of products and the customer experience.

Figure 5 outlines a proposal provisioning for the implementation of the MSC approach in fast fashion retailing through sustainability chatbots (SC). In step 1, a customer establishes a connection with the SC of a fast fashion retailer to know how to recycle and/or reuse their garments. The SC informs and engages the customer about durability, recycling, and the reuse of garments by suggesting educational modules on mindful and sustainable consumption (step 2). In step 3, the customer decides to proceed in the flow proposed by the SC that offers two options: increasing their clothing utilisation or recycling their garments (step 4).

If the customer chooses to increase their garment utilisation (step 4a), the SC offers four further options: the first one is to exchange their garments with other users to renew their wardrobe; the second is to rent used garments from other users; the third is to rent their own clothes so as not to leave them unused in the closet and; the fourth is to exchange their used garments with the retailer to receive discounts on upcoming purchases (step 5).

If the customer chooses to radically improve the recycling of their garments (step 4b), the SC offers four further options: the first is to sell their garments to other users, the second is to buy used garments from other users, the third is to transform their used clothes by giving them a new life (e.g., cup covers, hand warmers, bags, lamps, etc.) or a new design (e.g., personalisation of used garments). In the last option, the customer could donate their used clothes to non-profit organisations (step 6). 


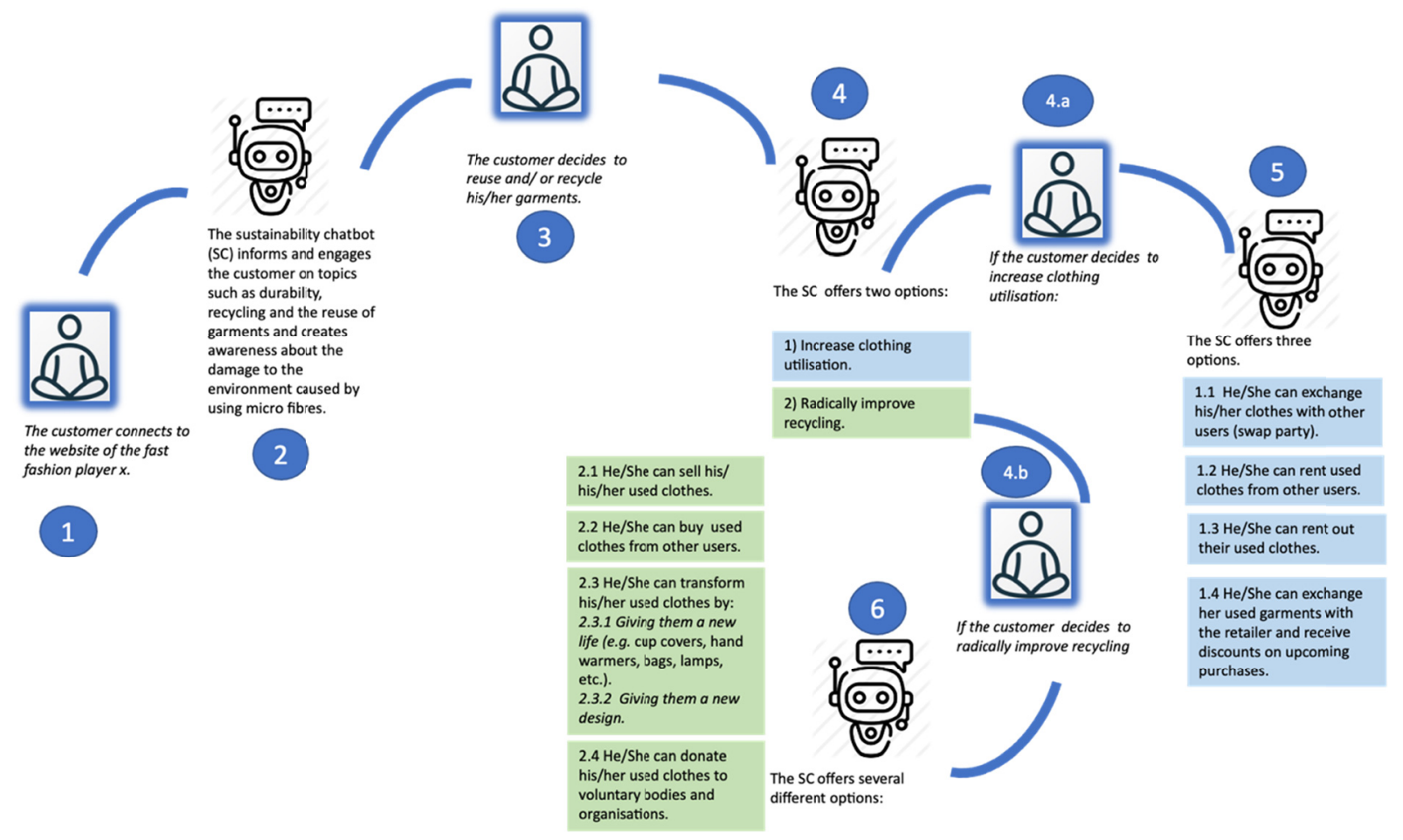

Figure 5. Implementing MSC approach through SC in fast fashion retailing

SC are innovative AI tools designed to implement the MSC approach. They offer retailers and customers the opportunity to co-create the value of sustainability.

To implement MSC in fast fashion retail, the first step for marketers is to refrain from aggressive marketing strategies. This means avoiding too low prices and aggressive promotions and/or excessive advertising in favor of an increase in clothing utilisation and recycling. In terms of increasing clothing utilization, garments could be designed with attributes that make them more durable and easier to exchange or rent to avoid repetitive, acquisitive, and aspirational consumption (Table 1). The introduction of new clothing has to include significant innovations rather than superficial changes. SC could be used to educate customers to reduce waste in fast fashion consumption. There may be tangible financial or other rewards that $\mathrm{SC}$ can offer to motivate customers to reduce their personal consumption. Marketers can help organize social membership clubs or community action committees such as swap parties with the help of SC to stimulate dialogue and exchange of garments among customers.

To increase the possibilities of recycling, the SC could direct the customer to new integrated platforms devoted to sustainability in which customers, retailers and non-profit organisations, collaborate in a virtuous way to radically improve the sale, customisation, or donation of used clothes.

\section{Discussion}

With the advent of the COVID-19 pandemic, customers have shown themselves to be much more sensitive to environmental, social, and ethical patterns than in previous decades. With the help of MSC and new technologies such as chatbots, customers could gradually change their habits, dismantling the old routines of overconsumption (Bick et al., 2018). The key is to create an ecosystem (Saviano et al., 2017) that encourages all parts of fast fashion to collaborate in a logic of exchange and value co-creation (Xie et al., 2016).

The MSC approach aims to use the power of the community to build an ecosystem devoted to sustainability, allowing the collaboration of multiple stakeholders along the value chain. The practices of mindful consumption combined with those of sustainability are able to create healthy mental habits and sustainable behaviours both from customers' and retailers' point of view. In fact, Milne et al. (2020) in their study on mindful consumption affirm that "if consumers also engage in mindfulness practices in conjunction with their mindful consumption activities, it is likely that the scope of their attention and change of habits will broaden to marketplace decision that also help their well-being across non-economic considerations, including their communities and the 
environment" (p. 9). In particular, the fast fashion industry has been recognised as one of the major polluting sectors (Grazzini et al., 2021) and for this reason it can be considered a perfect scope for the MSC approach defined in this study. From the assumption that fast fashion retailers are also working to become more sustainable (Forbes, 2018), this study aims to facilitate this process through SC. The MSC approach and SC, in fact, could influence customers' decisions on recycling or increasing clothing utilisation.

From a retailer point of view, the MSC approach is able to involve all the players in the fast fashion sector. Retailers may have to be invited to join consumer-envisioned provisioning in the long run to buy back (with coupons and discounts) clothing and garments from users to recycle them. SC and the analysis of big data could allow retailers to make more efficient and measurable decision-making processes in relation to the objectives of the sustainable development goals (SDGs), in an inclusive and fair way.

Marketing managers could provide through SC analytical approaches for improving and enabling innovation in three main ways:

1) Develop iterative design processes assisted by machine learning that allow rapid prototypes and tests to create user-centred clothing design. The goal is to design clothes that are optimal for how users can, want or need to use them rather than force users to adjust their behaviour to suit new designs.

2) Combine historical and real-time data of garments and users, increasing the circulation of apparel and the use of resources through prices and demand forecasts, predictive maintenance, and intelligent inventory management. For example, with SC it is possible to identify the right customer segment, such as young women who practice outdoors running, and garments can be rented, exchanged, or recycled according to customer's needs.

3) Improve the processes of sorting and disassembling products, regenerating components and recycling materials. For example, SC could help identify the knowledge and skills to find the right material and avoid plastic microfibers.

\section{Limitations and Future Research}

The study has some limitations, which may lead to future research. The main limitation is that the MSC approach is at an early conceptual stage and needs to be evaluated and empirically validated. Nevertheless, this study opens up new perspectives for future research to identify how to embed sustainability into customers' choices and retailers' strategies. Mindfulness may offer relevant advancements in knowledge for the definition of a new path aiming to enrich the consumer transformative research framework according to a sustainability perspective (Csikszentmihalyi, 1990; Brown \& Ryan, 2003; Brown \& Kasser, 2005; Brown et al., 2007; Amel et al., 2009; Goleman, 2009; Jacob et al., 2009; Sheth et al., 2011; Ericson et al., 2014).

Future research is required to identify the levers, which act to promote the MSC approach. Furthermore, SC provisioning requires implementation and measurements to verify the relationship between mindful and sustainability-oriented customer behaviours using both qualitative and quantitative approaches. The MCS approach should also be studied and applied to other industrial sectors that are particularly polluting and harmful to the environment.

\section{Conclusion}

Even before the COVID-19 crisis, sustainability has been a challenge for the fast fashion sector. Conversely, unconscious fashion purchases, triggered by marketing strategies that do not engage the customer in a conscious and sustainable consumption, but only stimulate demand through the continuous launch of new garment collections, have defined success in terms of the turnover of the industry to the detriment of both the environment and the community. However, to survive this pandemic and emerge stronger, fast fashion retailers must integrate sustainability into their new growth strategies.

In the post-COVID-19 pandemic world, trends demonstrate that the "new mindful customer" will prioritise trust and purpose and will likely evaluate firms based on how they acted in terms of sustainability practices during and after the crisis. Transparency will be extremely relevant for all interested parties.

An important lesson from the COVID-19 era is that health, safety, and prosperity are inherently collective rather than individual activities and the fast fashion sector is no different. It may not be easy to manage a one-off economic crisis by generating mindful actions in favour of environmental and social concerns. For this reason, the new MSC approach could help marketing managers rebuild a more sustainable fast fashion industry.

The MSC approach implemented with the help of SC in the fast fashion sector has three notable key takeaways:

1) MSC is an integrated approach to the theoretical development of mindful and sustainable consumption that offers new light on the complexity surrounding sustainability, encouraging customers and retailers to 
implement a systemic rather than individualistic perspective.

2) The SC is an innovative AI-tool that could drive mindfulness and sustainability in consumption choices and retailers' strategies for personal, social, and environmental well-being.

3) Marketing managers and retailers may innovate their actions and processes to include the complete integration of sustainability into their business strategies triggering virtuous mechanisms that co-create value starting from the protection of environmental resources in one of the most polluting sectors such as fast fashion, avoiding the exploitation of low-cost labour and creating emotional awareness in customers' choices through the information as well as the exchange, reuse, recycling of used fast fashion garments in the most inclusive way.

\section{References}

Acharya, A., Singh, S. K., Pereira, V., \& Singh, P. (2018). Big data, knowledge co-creation and decision making in fashion industry. International Journal of Information Management, 42, 90-101. https://doi.org/10.1016/j.ijinfomgt.2018.06.008

Amel, E., Manning, C., \& Scott, B. (2009). Mindfulness and Sustainable Behavior: Pondering Attention and Awareness as Means for Increasing Green Behavior. Ecopsychology, 1, 14-25. https://doi.org/10.1089/eco.2008.0005

Anguelov, N. (2015). The Dirty Side of the Garment Industry: Fast Fashion and Its Negative Impact on Environment and Society (1st ed.). CRC Press. https://doi.org/10.1201/b18902

Aspy, D. J., \& Proeve, M. (2017). Mindfulness and Loving-Kindness Meditation: Effects on Connectedness to Humanity and to the Natural World. Psychological Reports, 120(1), 102-117. https://doi.org/10.1177/0033294116685867

Badham, R., \& King, E. (2021). Mindfulness at work: A critical re-view. Organization, 28(4), 531-554. https://doi.org/10.1177/1350508419888897

Baer, R. A. (2003). Mindfulness training as a clinical intervention: A conceptual and empirical review. Clinical Psychology: Science and Practice, 10(2), 125-143. https://doi.org/10.1093/clipsy.bpg015

Bahl, S., Milne, G. R., Ross, S. M., Mick, D. G., Grier, S. A., Chugani, S. K., ... Boesen-Mariani, S. (2016). Mindfulness: Its Transformative Potential for Consumer, Societal, and Environmental Well-Being. Journal of Public Policy \& Marketing, 35(2), 198-210. https://doi.org/10.1509/jppm.15.139

Barbaro, N., \& Pickett, S. M. (2016). Mindfully green: Examining the effect of connectedness to nature on the relationship between mindfulness and engagement in pro-environmental behavior. Personality and Individual Differences, 93, 137-142. https://doi.org/10.1016/j.paid.2015.05.026

Barnes, L., \& Lea - Greenwood, G. (2006). Fast fashioning the supply chain: Shaping the research agenda. Journal of Fashion Marketing and Management, 10(3), 259-271. https://doi.org/10.1108/13612020610679259

Barnes, L., \& Lea-Greenwood, G. (2010). Fast fashion in the retail store environment. International Journal of Retail and Distribution Management, 38(10), 760-772. https://doi.org/10.1108/09590551011076533

Benson, A. L. (2008). To Buy or Not to Buy: Why We Overshop and How to Stop. Boston: Trumpeter Books.

Bick, R., Halsey, E., \& Ekenga, C. C. (2018). The global environmental injustice of fast fashion. Environ Health, 17, 92. https://doi.org/10.1186/s12940-018-0433-7

Bishop, S. R., Lau, M., Shapiro, S., Carlson, L., Anderson, N., \& Carmody, J. (2004). Mindfulness: A proposed operational definition. Clinical Psychology: Science and Practice, 11(3), 230-241. https://doi.org/10.1093/clipsy.bph077

Black, D. S. (2011). A brief definition of mindfulness. Retrieved from http://www. mindfulexperience.org

Brady, M. K. (2018). How can looking at the whole picture help you serve customers? In Mapping Out Marketing: Navigation Lessons. London: Routledge. https://doi.org/10.4324/9781315112602-28

Brown, K. W., \& Kasser, T. (2005). Are Psychological and Ecological Well-being Compatible? The Role of Values, Mindfulness, and Lifestyle. Social Indicators Research, 74, 349-368. https://doi.org/10.1007/s11205-004-8207-8

Brown, K. W., \& Ryan, R. M. (2003). The benefits of being present: Mindfulness and its role in psychological well-being. Journal of Personality and Social Psychology, 84(4), 822-848. 
https://doi.org/10.1037/0022-3514.84.4.822

Brown, K. W., Ryan, R. M., \& Creswell, J. D. (2007). Mindfulness: Theoretical Foundations and Evidence for its Salutary Effects. Psychological Inquiry, 18(4), 211-237. https://doi.org/10.1080/10478400701598298

Brown, W. H., Googe, H. S., McIver, K. L., \& Rathel, J. M. (2009). Effects of Teacher-Encouraged Physical Activity on Preschool Playgrounds. Journal of Early Intervention, 31(2), 126-145. https://doi.org/10.1177/1053815109331858

Bruce, M., \& Daly, L. (2006). Buyer behaviour for fast fashion. Journal of Fashion Marketing and Management, 10(3), 329-344. https://doi.org/10.1108/13612020610679303

Burroughs, J. E., \& Rindfleisch, A. (2002). Materialism and well-being: A conflicting values perspective. Journal of Consumer Research, 29(3), 348-370. https://doi.org/10.1086/344429

Cachon, G. P., \& Swinney, R. (2011). The Value of Fast Fashion: Quick Response, Enhanced Design, and Strategic Consumer Behavior. Management Science, 57(4), 778-795. https://doi.org/10.1287/mnsc. 1100.1303

Chambers, S., Fasano, C., Papapetrou, E. et al. (2009). Highly efficient neural conversion of human ES and iPS cells by dual inhibition of SMAD signaling. Nat Biotechnol, 27, 275-280. https://doi.org/10.1038/nbt.1529

Chan, K. W., \& Li, S. Y. (2010). Understanding consumer-to-consumer interactions in virtual communities: The salience of reciprocity. Journal of Business Research, 63(9), 1033-1040. https://doi.org/10.1016/j.jbusres.2008.08.009

Charm, T., Hwang, T., Leon, A., Sancho Mazzara, D., Lu, N., Medalsy, J., ... Robinson, K. (2021). McKinsey Survey on US consumer sentiment and behaviors during the coronavirus crisis. Retrieved from $\mathrm{https} / / /$ www.mckinsey.com/business-functions/marketing-and-sales/our-insights/survey-us-consumer-senti ment-during-the-coronavirus-crisis

Chatzisarantis, N. L., \& Hagger, M. S. (2007). Mindfulness and the intention-behavior relationship within the theory of planned behavior. Personality \& Social Psychology Bulletin, 33(5), 663-676. https://doi.org/10.1177/0146167206297401

Chen, M.-K., Wang, Y.-H., \& Hung, T.-Y. (2014). Establishing an order allocation decision support system via learning curve model for apparel logistics. Journal of Industrial and Production Engineering, 31(5), 274-285. https://doi.org/10.1080/21681015.2014.951406

Christopher, M., Lowson, R., \& Peck, H. (2004). Creating agile supply chains in the fashion industry. International Journal of Retail \& Distribution Management, 32(8), 367-376. https://doi.org/10.1108/09590550410546188

Cobbing, M., \& Vicaire, Y. (2016). Timeout for fast fashion. Retrieved 2019, from https://www.greenpeace.org/archive-international/Global/international/brief-ings/toxics/2016/Fact-Sheet-Ti meout-for-fast-fashion.pdf

Condon, P., Desbordes, G., Miller, W. B., \& DeSteno, D. (2013). Meditation Increases Compassionate Responses to Suffering. Psychological Science, 24(10), 2125-2127. https://doi.org/10.1177/0956797613485603

Costello, A., Abbas, M., Allen, A., Ball, S., Bell, S., Bellamy, R. et al. (2009). Managing the health effects of climate change. Lancet and University College London Institute for Global Health Commission. The Lancet, 373(9676), 1693-1733. https://doi.org/10.1016/S0140-6736(09)60935-1

Csikszentmihalyi, M. (1990). Flow: The Psychology of Optimal Experience. Journal of Leisure Research, 24(1), 93-94. https://doi.org/10.1080/00222216.1992.11969876

de Groot, J., \& Steg, L. (2008). Value orientations to explain environmental attitudes and beliefs: How to measure egoistic, altruistic and biospheric value orientations. Environment and Behavior, 40, 330-354. https://doi.org/10.1177/0013916506297831

de Groot, J. I. M., \& Thøgersen, J. (2018). Values and Pro-Environmental Behaviour. In L. Steg, A. van de Berg \& J. I. M. de Groot (Eds.), Environmental Psychology (pp. 167-178). https://doi.org/10.1002/9781119241072.ch17

Dempt, F. (2016). Futuregram. Retrieved June 24, 2017, from http://futuregram.trendone.com/index.html\#einstieg

Dennis, C., Alamanos, E., Papagiannidis, S., \& Bourlakis, M. (2016). Does social exclusion influence multiple 
channel use? The interconnections with community, happiness, and well-being. Journal of Business Research, 69(3), 1061-1070. https://doi.org/10.1016/j.jbusres.2015.08.019

Djernis, L., Poulsen, S., Dahlgaard, J., \& O'Toole, M. (2019). A Systematic Review and Meta-Analysis of Nature-Based Mindfulness: Effects of Moving Mindfulness Training into an Outdoor Natural Setting. International Journal of Environmental Research and Public Health, 16(17), 3202. https://doi.org/10.3390/ijerph16173202

Donald, J. N., Sahdra, B. K., Van Zanden, B., Duineveld, J. J., Atkins, P. W. B., Marshall, S. L., \& Ciarrochi, J. (2018). Does your mindfulness benefit others? A systematic review and meta-analysis of the link between mindfulness and prosocial behaviour. British Journal of Psychology, 110(1), 101-125 https://doi.org/10.1111/bjop.12338

Ericson, T., Kjnstad, B. G., \& Barstad, A. (2014). Mindfulness and sustainability. Ecological Economics, 104, 73-79. https://doi.org/10.1016/j.ecolecon.2014.04.007

Fernie, J., \& Sparks, L. (Eds.) (2004). Logistics and retail management. London: Kogan Page.

Fischer, D., Stanszus, L. S., Geiger, S., Grossman, P., \& Schrader, U. (2017). Mindfulness and sustainable consumption: A systematic literature review of research approaches and findings. Journal of Cleaner Production, 162, 544-558. https://doi.org/10.1016/j.jclepro.2017.06.007

Forbes. (2018). Luxury Brands that Let You Shop for A Cause. Retrieved from https://www.forbes.com/sites/forbes-finds/2018/08/19/7-luxury-brands-that-let-you-shop-for-a-cause/\#40b6 c4fe $73 \mathrm{~b} 7$

Fuentes, C., \& Sörum, N. (2019). Agencing ethical consumers: Smartphone apps and the socio-material reconfiguration of everyday life. Consumption Markets \& Culture, 22(2), 131-156, https://doi.org/10.1080/10253866.2018.1456428

Garland, E. L., Farb, N. A., Goldin, R. P., \& Fredrickson, B. L. (2015). Mindfulness Broadens Awareness and Builds Eudaimonic Meaning: A Process Model of Mindful Positive Emotion Regulation. Psychological Inquiry, 26(4), 293-314. https://doi.org/10.1080/1047840X.2015.1064294

Gatersleben, B. (2018). Measuring Environmental Behaviour. In L. Steg, A. van de Berg \& J. I. M. de Groot (Eds.), Environmental Psychology (pp. 155-166). https://doi.org/10.1002/9781119241072.ch16

Gilpin, R. (2008). The use of Theravāda Buddhist practices and perspectives in mindfulness-based cognitive therapy. Contemporary Buddhism, 9(2), 227-251. https://doi.org/10.1080/14639940802556560

Goleman, D. (2009). Emotional Intelligence: Why It Can Matter More Than IQ. London: Bloomsbury Publishing Plc.

Grazzini, L., Acuti, D., \& Aiello, G. (2020). Solving the puzzle of sustainable fashion consumption: The role of consumers' implicit attitudes and perceived warmth. Journal of Cleaner Production, 287. https://doi.org/10.1016/j.jclepro.2020.125579

Grossman, P., Niemann, L., Schmidt, S., \& Walach, H. (2004). Mindfulness-based stress reduction and health benefits. A meta-analysis. Journal of Psychosomatic Research, 57(1), 35-43. https://doi.org/10.1016/S0022-3999(03)00573-7

Guo, Z. X., Wong, W. K., Leung, S. Y. S., \& Li, M. (2011). Applications of artificial intelligence in the apparel industry: A review. Textile Research Journal, 81(18), 1871-1892. https://doi.org/10.1177/0040517511411968

Hamann, G., \& Ivtzan, I. (2016). 30 Minutes in Nature a Day Can Increase Mood, Well-Being, Meaning in Life and Mindfulness: Effects of a Pilot Programme. Social Inquiry into Well-Being, 2(2), 34-46. https://doi.org/10.13165/SIIW-16-2-2-04

Hanh, T. N. (1976). The miracle of mindfulness: A manual for meditation. Boston: Beacon.

Hanley, A. W., Baker, A. K., \& Garland, E. L. (2017). Self-interest may not be entirely in the interest of the self: Association between self- lessness, dispositional mindfulness and psychological well-being. Personality and Individual Differences, 117, 166-171. https://doi.org/10.1016/j.paid.2017.05.045

Hedlund-de Witt, A., de Boer, J., \& Boersema, J. J. (2014). Exploring inner and outer worlds: A quantitative study of worldviews, environmental attitudes, and sustainable lifestyles. Journal of Environmental Psychology, 37, 40-54. https://doi.org/10.1016/j.jenvp.2013.11.005 
Hölzel, B. K., Lazar, S. W., Gard, T., Schuman-Olivier, Z., Vago, D. R., \& Ott, U. (2011). How does mindfulness meditation work? Proposing mechanisms of action from a conceptual and neural perspective. Perspectives on Psychological Science, 6(6), 537-559. https://doi.org/10.1177/1745691611419671

Howell, A. J., Dopko, R. L., Passmore, H. A., \& Buro, K. (2011). Nature connectedness: Associations with well-being and mindfulness. Personality and Individual Differences, 51(2), 166-171. https://doi.org/10.1016/j.paid.2011.03.037

Howell, K. E. (2013). An introduction to the philosophy of methodology. SAGE Publications Ltd https://doi.org/10.4135/9781473957633

Hunecke, M., \& Richter, N. (2019). Mindfulness, Construction of Meaning, and Sustainable Food Consumption. Mindfulness, 10(3), 446-458. https://doi.org/10.1007/s12671-018-0986-0.

Ives, C. D., Freeth, R., \& Fischer, J. (2019). Inside-out sustainability: The neglect of inner worlds. Ambio. https://doi.org/10.1007/s13280-019-01187-w

Jacob, J. C., Brinkerhoff, M. B., \& Jovic, E. (2009). Personal and Planetary Well-Being: Mindfulness Meditation, Pro-Environmental Behavior and Personal Quality of Life in a Survey from the Social Justice and Ecological Sustainability Movement. Social Indicators Research, 93, 275-294. https://doi.org/10.1007/s11205-008-9308-6

Kabat-Zinn, J. (1994). Wherever you go, there you are: Mindfulness meditation in everyday life. New York: Hyperion Books.

Kabat-Zinn, J. (2003). Mindfulness-based interventions in context: Past, present, and future. Clinical Psychology: Science \& Practice, 10(2), 144-156. https://doi.org/10.1093/clipsy.bpg016

Kabat-Zinn, J. (2013). Full catastrophe living: using the wisdom of your body and mind to face stress, pain, and illness (Rev. and updated ed., Bantam Books trade paperback ed.). New York: Bantam Books.

Kabat-Zinn, J. (2017). Too Early to Tell: The Potential Impact and Challenges-Ethical and Otherwise-Inherent in the Mainstreaming of Dharma in an Increasingly Dystopian World. Mindfulness, 8(5), 1125-1135. https://doi.org/10.1007/s12671-017-0758-2

Kabat-Zinn, J., Lipworth, L., \& Burney, R. (1985). The clinical use of mindfulness meditation for the self-regulation of chronic pain. Journal of Behavioral Medicine, 8, 163-190. https://doi.org/10.1007/BF00845519

Kabat-Zinn, J., Lipworth, L., Burney, R., \& Sellers, W. (1987). Four-year follow-up of a meditation-based program for the self-regulation of chronic pain: Treatment outcome and compliance. Clinical Journal of Pain, 2, 159-173. https://doi.org/10.1097/00002508-198602030-00004

Kachaner, N., Nielsen, J., Portafaix, A., \& Rodzko, F. (2020). BCG Survey on Covid-19 and Environment. Retrieved from https://www.bcg.com/it-it/publications/2020/pandemic-is-heightening-environmental-awareness

Kasser, T. (2017). Living both well and sustainably: A review of the literature, with some reflections on future research, interventions and policy. Philosophical Transactions of the Royal Society A: Mathematical, Physical and Engineering Sciences, 375(2095). https://doi.org/10.1098/rsta.2016.0369

Kasser, T., Rosenblum, K. L., Sameroff, A. J., Deci, E. L., Niemiec, C. P., Ryan, R. M., ... Hawks, S. (2014). Changes in materialism, changes in psychological well - being. Evidence from three longitudinal studies and an intervention experiment. Motivation and Emotion, 38, 1-22. https://doi.org/10.1007/s11031-013-9371-4

Kastanakis, M. N., \& Balabanis, G. (2012). Between the mass and the class: Antecedents of the "bandwagon" luxury consumption behavior. Journal of Business Research, 65(10), 1399-1407. https://doi.org/10.1016/j.jbusres.2011.10.005

Kastanakis, M. N., \& Balabanis, G. (2014). Explaining variation in conspicuous luxury consumption: An individual differences' perspective. Journal of Business Research, 67(10), 2147-2154. https://doi.org/10.1016/j.jbusres.2014.04.024

Kilbourne, W. E. (2006). The role of the dominant social paradigm in the quality of life/environmental interface. Applied Research in Quality of Life, 1, 39-61. https://doi.org/10.1007/s11482-006-9004-0

Klöckner, C. A., \& Verplanken, B. (2019). Yesterday's Habits Preventing Change for Tomorrow? About the 
Influence of Automaticity on Environmental Behaviour. In L. Steg, A. van de Berg \& J. I. M. de Groot (Eds.), Environmental Psychology (pp. 238-250). https://doi.org/10.1002/9781119241072.ch24

Kreplin, U., Farias, M., \& Brazil, I. A. (2018). The limited prosocial effects of meditation: A systematic review and meta-analysis. Nature Scientific Reports, 8(1), 1-10. https://doi.org/10.1038/s41598-018-20299-z

Lee, C. K. H., Choy, K. L., Law, K. M. Y., \& Ho, G. T. S. (2012). An intelligent system for production resources planning in Hong Kong garment industry (pp. 889-893). In IEEE International Conference on Industrial Engineering and Engineering Management. https://doi.org/10.1109/IEEM.2012.6837868

Leiberg, S., Klimecki, O., \& Singer, T. (2011). Short-term compassion training increases prosocial behavior in a newly developed prosocial game. PLOS ONE, 6, e17798. https://doi.org/10.1371/journal.pone.0017798

Lertwannawit, A., \& Mandhachitara, R. (2012). Interpersonal effects on fashion consciousness and status consumption moderated by materialism in metropolitan men. Journal of Business Research, 65(10), 1408-1416. https://doi.org/10.1016/j.jbusres.2011.10.006

Lim, D., Condon, P., \& DeSteno, D. (2015). Mindfulness and Compassion: An Examination of Mechanism and Scalability. PLoS ONE, 10(2), e0118221. https://doi.org/10.1371/journal.pone.0118221

Livingstone, L. (2019). Taking Sustainability to Heart-Towards Engaging with Sustainability Issues Through Heart-Centred Thinking. Sustainability and the Humanities, 455-468. https://doi.org/10.1007/978-3-319-95336-6_26

Loy, L. S., \& Reese, G. (2019). Hype and hope? Mind-body practice predicts pro-environmental engagement through global identity. Journal of Environmental Psychology, 66(August), 101340. https://doi.org/10.1016/j.jenvp.2019.101340

Lutz, A., Slagter, H. A., Dunne, J. D., \& Davidson, R. J. (2008). Attention regulation and monitoring in meditation. Trends in Cognitive Sciences, 12(4), 163-169. https://doi.org/10.1016/j.tics.2008.01.005

Marlatt, A. G., \& Kristeller, J. L. (1999). Mindfulness and meditation. In W. R. Miller (Ed.), Integrating spirituality into treatment (pp. 67-84). Washington D.C: American Psychological Association. https://doi.org/10.1037/10327-004

Mick, D., Pettigrew, S., Pechmann, C., \& Ozanne, J. (2012). Transformative Consumer Research: For Personal and Collective Well-Being. Taylor and Francis, 333-352. https://doi.org/10.4324/9780203813256

Milne, G. R., Villarroel Ordenes, F., \& Kaplan, B. (2020). Mindful Consumption: Three Consumer Segment Views. Australasian Marketing Journal, 28(1), 3-10. https://doi.org/10.1016/j.ausmj.2019.09.003

Moore, A., \& Malinowski, P. (2009). Meditation, Mindfulness and Cognitive Flexibility. Consciousness and Cognition, 18, 176-186. https://doi.org/10.1016/j.concog.2008.12.008

Muller, A., Schader, C., El-Hage Scialabba, N., Brüggemann, J., Isensee, A., Erb, K. H., ... Niggli, U. (2017). Strategies for feeding the world more sustainably with organic agriculture. Nature Communications, $8(1)$, 1290. https://doi.org/10.1038/s41467-017-01410-w

Nasira, G. M., \& Banumathi, P. (2014). An intelligent system for automatic fabric inspection. Asia-Pacific Journal of Information Technology and Multimedia, 13(6), 308-312.

Nayak, R., \& Padhye, R. (2018). Artificial intelligence and its application in the apparel industry. Automation in Garment Manufacturing, 109-138. https://doi.org/10.1016/B978-0-08-101211-6.00005-7

O'Brien, K. (2018). Is the $1.5^{\circ} \mathrm{C}$ target possible? Exploring the three spheres of transformation. Current Opinion in Environmental Sustainability, 31, 153-160. https://doi.org/10.1016/j.cosust.2018.04.010

Panesar, K. (2020). Conversational artificial intelligence - demystifying statistical vs linguistic NLP solutions. Journal of Computer-Assisted Linguistic Research, 4(1), 47-79. https://doi.org/10.4995/jclr.2020.12932

Panno, A., Giacomantonio, M., Carrus, G., Maricchiolo, F., Pirchio, S., \& Mannetti, L. (2018). Mindfulness, Pro-environmental Behavior, and Belief in Climate Change: The Mediating Role of Social Dominance. Environment and Behavior, 50(8), 864-888. https://doi.org/10.1177/0013916517718887

Rauturier, S. (2018). What is Fast Fashion. Retrieved 2019, from https:/goodo-nyou.eco/what-is-fast-fashion/

Richins, M. L., \& Dawson, S. (1992). A consumer values orientation for materialism and its measurement: Scale development and validation. Journal of Consumer Research, 19(3), 303-316. https://doi.org/10.1086/209304 
Rosenberg, E. L. (2005). Mindfulness and consumerism. In T. Kasser \& A. D. Kanner (Eds.), Psychology and consumer culture: The struggle for a good life in a materialistic world (pp. 107-125). American Psychological Association. https://doi.org/10.1037/10658-007

Saviano, M., Barile, S., Spohrer, J. C., \& Caputo, F. (2017). A service research contribution to the global challenge of sustainability. Journal of Service Theory and Practice, 27(5), 951-976. https://doi.org/10.1108/JSTP-10-2015-0228

Schulte, B. (2014). Overwhelmed: Work, Love, and Play When No One Has the Time. New York: Sarah Crichton Books.

Schutte, N. S., \& Malouff, J. M. (2018). Mindfulness and connectedness to nature: A meta-analytic investigation. Personality and Individual Differences, 127(February), 10-14. https://doi.org/10.1016/j.paid.2018.01.034

Shapiro, S. L., Schwartz, G. E., \& Bonner, G. (1998). Effects of Mindfulness-Based Stress Reduction on Medical and Premedical Students. Journal of Behavioral Medicine, 21, 581-599. https://doi.org/10.1023/A:1018700829825

Sheridan, M., Moore, C., \& Nobbs, K. (2006). Fast fashion requires fast marketing: The role of category management in fast fashion positioning. Journal of Fashion Marketing and Management, 10(3), 301-315. https://doi.org/10.1108/13612020610679286

Sheth, J. N., Sethia, N. K., \& Srinivas, S. (2011). Mindful consumption: A customer-centric approach to sustainability. Journal of the Academy of Marketing Science, 39, 21-39. https://doi.org/10.1007/s11747-010-0216-3

Siegel, D. J. (2001). Toward an Interpersonal Neurobiology of the Developing Mind: Attachment Relationships, "Mindsight," and Neural Integration. Infant Mental Health Journal, 22, 67-94. https://doi.org/10.1002/1097-0355(200101/04)22:1<67::AID-IMHJ3>3.0.CO;2-G

Singer, T., \& Bolz, M. (Eds.). (2013). Compassion: Bridging practice and science. Leipzig: Max Planck Institute for Human Cognitive and Brain Sciences.

Singer, T., \& Engert, V. (2019). It matters what you practice: Differential training effects on subjective experience, behavior, brain and body in the ReSource Project. Current Opinion in Psychology, 28, 151-158. https://doi.org/10.1016/j.copsyc.2018.12.005

Siqueira, R. P., \& Pitassi, C. (2016). Sustainability-oriented innovations: Can mindfulness make a difference? Journal of Cleaner Production, 139, 1181-1190. https://doi.org/10.1016/j.jclepro.2016.08.056.

Sohn, D., \& Choi, S. M. (2014). Measuring expected interactivity: Scale development and validation. New Media \& Society, 16(5), 856-870. https://doi.org/10.1177/1461444813495808

Steg, L. (2016). Values, Norms, and Intrinsic Motivation to Act Proenvironmentally. Annual Review of Environment and Resources, 41(1), 277-292. https://doi.org/10.1146/annurev-environ-110615-085947

Steg, L., Perlaviciute, G., van der Werff, E., \& Lurvink, J. (2014). The Significance of Hedonic Values for Environmentally Relevant Attitudes, Preferences, and Actions. Environment and Behavior, 46(2), 163-192. https://doi.org/10.1177/0013916512454730

Stottlemire, K. (2017). Fast Fashion vs. Sustainable Fashion. Retrieved 2019, from https://www.hercampus.com/school/lmu/fast-fashion-vs-sustainable-fashion

Sull, D., \& Turconi, S. (2008). Fast fashion lessons. Business Strategy Review, 19, 4-11. https://doi.org/10.1111/j.1467-8616.2008.00527.x

Thiermann, U. B., \& Sheate, W. R. (2020). Motivating individuals for social transition: The 2-pathway model and experiential strategies for pro-environmental behaviour. Ecological Economics, 174, 106668. https://doi.org/10.1016/j.ecolecon.2020.106668

Unsworth, S., Palicki, S. K., \& Lustig, J. (2016). The Impact of Mindful Meditation in Nature on Self-Nature Interconnectedness. Mindfulness, 7(5), 1052-1060. https://doi.org/10.1007/s12671-016-0542-8

Van Dam, N. T., van Vugt, M. K., Vago, D. R., Schmalzl, L., Saron, C. D., Olendzki, A. et al. (2018). Mind the Hype: A Critical Evaluation and Prescriptive Agenda for Research on Mindfulness and Meditation. Perspectives on Psychological Science, 13(1), 36-61. https://doi.org/10.1177/1745691617709589

Vargo, S. L., Maglio, P. P., \& Akaka, M. A. (2008). On value and value co-creation: A service systems and service logic perspective. European Management Journal, 6(3), 154-152. 
https://doi.org/10.1016/j.emj.2008.04.003

Wamsler, C. (2018). Mind the gap: The role of mindfulness in adapting to increasing risk and climate change. Sustainability Science, 13(4), 1121-1135. https://doi.org/10.1007/s11625-017-0524-3.

Wamsler, C. (2019). Contemplative Sustainable Futures: The Role of Individual Inner Dimensions and Transformation in Sustainability Research and Education. In W. Leal, F. Adriana \& C. Mccrea (Eds.), Sustainability and the Humanities (pp. 359-373). https://doi.org/10.1007/978-3-319-95336-6_20

Wamsler, C., Brossmann, J., Hendersson, H., Kristjansdottir, R., McDonald, C., \& Scarampi, P. (2017). Mindfulness in sustainability science, practice, and teaching. Sustainability Science, 1-20. https://doi.org/10.1007/s11625-017-0428-2

Wang, Y., \& Petrina, S. (2013). Using Learning Analytics to Understand the Design of an Intelligent Language Tutor-Chatbot Lucy. International Journal of Advanced Computer Science and Applications, 4. https://doi.org/10.14569/IJACSA.2013.041117

Werner, A., Spiller, A., \& Meyerding, S. G. H. (2020). The yoga of sustainable diets: Exploring consumers mind and spirit. Journal of Cleaner Production, 243, 118473. https://doi.org/10.1016/j.jclepro.2019.118473

Whitburn, J., Linklater, W., \& Abrahamse, W. (2019). Meta-analysis of human connection to nature and proenvironmental behavior. Conservation Biology, 1-31. https://doi.org/10.1111/cobi.13381.

Winter, C. (2007). The intrinsic, instrumental and spiritual values of natural area visitors and the general public: A comparative study. Journal of Sustainable Tourism, 15(6), 599-614. https://doi.org/10.2167/jost686.0

Zarley Watson, M., \& Yan, R. (2013). An exploratory study of the decision processes of fast versus slow fashion consumers. Journal of Fashion Marketing and Management, 17(2), 141-159. https://doi.org/10.1108/JFMM-02-2011-0045

Zhan, L., \& He, Y. (2012). Understanding luxury consumption in China: Consumer perceptions of best-known brands. Journal of Business Research, 65(10), 1452-1460. https://doi.org/10.1016/j.jbusres.2011.10.011

\section{Copyrights}

Copyright for this article is retained by the author, with first publication rights granted to the journal.

This is an open-access article distributed under the terms and conditions of the Creative Commons Attribution license (http://creativecommons.org/licenses/by/4.0/). 